\title{
Structural analysis of W7-X: From design to assembly and operation
}

V. Bykov*, F. Schauer, K. Egorov, P. van Eeten, J. Fellinger, M. Sochor, N. Jaksic, A. Tereshchenko, A. Dübner, A. Dudek, D. Zacharias, D. Hathiramani, P. Czarkowski, Q. Yang, T. Bergmann, S. Freundt and W7-X team

Max-Planck-Institute für Plasmaphysik, Euratom Association, Teilinstitut Greifswald, Wendelsteinstrasse 1, D-17491 Greifswald, Germany 
Abstract - The Wendelstein 7-X (W7-X) modular stellarator is in the assembly phase at the Max-Planck-Institut für Plasmaphysik in Greifswald, Germany. The design of the "basic machine", i.e. without in-vessel components, diagnostics and periphery, is largely completed, structural parameters such as bolt preload, initial conditions for contact elements, etc. are defined, and most of the components are manufactured and partly assembled. Therefore, the focus of structural analysis was shifted towards fast analyses of nonconformities, changes in the assembly procedure, and exploration of operational limits. Assembly-related work is expected to continue until commissioning of the machine, however, with decreasing intensity. In parallel the analysis requirements for in-vessel components, diagnostics and periphery will increase.

This paper focuses on the most remarkable results, on special problems which had to be solved, on strategic issues like parameterization, complex finite element model structuring and benchmarking with alternative models in different codes, on assumptions of reasonable safety margins and expected tolerances, and on confirmation of analysis results by tests. Finally it highlights some lessons learned so far, which might be relevant also for other large fusion machines, and gives an outlook on future work.

Keywords: Stellarator, Wendelstein 7-X, Finite-element analysis, Magnet system, Cryostat system 


\section{Introduction}

Wendelstein 7-X (W7-X) will be the largest stellarator in the world with an average major radius of $5.5 \mathrm{~m}$, an average minor plasma radius of $0.53 \mathrm{~m}$, and a total weight of $725 \mathrm{t}$. It shall operate at reactor relevant plasma parameters [1]. The first three modules of the magnet system (out of 5) have been successfully completed within schedule and are already installed in the torus hall $[2,3]$.

The main structural components of $\mathrm{W} 7-\mathrm{X}$ are the magnet system, and the cryostat system (Fig. 1).

The W7-X magnet system consists of 50 super-conducting nonplanar coils (NPC), 20 superconducting planar coils (PLC), and the mechanical structure encompassing the central support structure (CSS) and the inter-coil support structure. The CSS stands on the machine base (MB) by 10 cryolegs (see Fig. 2). The NPCs have complex 3D geometry to ensure the required magnet field configuration (Fig. 3). The coils are arranged toroidally in five equal modules, with each one consisting of two flip-symmetric half modules. One half module includes five differently shaped NPCs and two PLCs. Each NPC and PLC is fastened to the CSS by two central support elements (CSE). The CSE is a bolted connection with possible opening of the flange. The narrow support elements (NSE, 29 per half module) and the lateral support elements (LSE) connect adjacent NPC casings on the high field and on the low field sides of the machine, respectively (Fig. 3). The NSEs are sliding contacts, while LSEs are welded connections with the exception of the inter-module ones which are bolted. The planar support elements (PSE) connect the two types of PLC (A, B) to the NPC. One PSE per coil (PSE-A1, PSE-B1) is a fixed bolted connection, while other PSEs follow the NSE design [4].

The cryostat system consists of the plasma vessel (PV), outer vessel (OV), the ports and the 
machine base. The PV corresponds to the twisted shape of the plasma and is manufactured from $17 \mathrm{~mm}$ thick stainless steel (SS) segments. 254 ports with different shapes (round, oval, and rectangular) connect the PV to the $25 \mathrm{~mm}$ thick SS OV. The magnet system is located between the PV and the OV, and kept at cryogenic temperature $(4 \mathrm{~K})$ in high vacuum $\left(\sim 10^{-4}\right.$ Pa) [5].

A reliable prediction of the $\mathrm{W} 7-\mathrm{X}$ structural behaviour is only possible with extensive finite element (FE) analyses [6-9].

The magnet system analysis is a most challenging task due to the complexity of the coil geometries and the non-linear behaviour of the coil support system. The whole structure is highly sensitive to initial contact gap openings, contact friction factor, coil stiffness, bolt pretension, etc.

The strategy of W7-X structural analysis [9] is similar to the approach for many other unique and large facilities. Two types of models are intensively used: global models (GMs) for the choice of main system parameters, and local models for detail analysis of the critical components.

The magnet system global FE model includes the coils and their support structure, the cryostat system global FE model encompasses the OV, the PV, the ports with bellows, and the MB. Both global models are analysed separately with some specific assumptions [6].

Two additional GMs have been created and analysed for auxiliary systems of the magnet system: (1) the cryopipe system GM [10] and (2) the bus-bar GM [11]. Both GMs represent complex mechanical structures that include relatively long and flexible lines together with numerous supports which are mounted on the coils, the CSS, and other components. The supports for both systems are non-linear due to intentionally introduced gaps, and the cryopipe system includes numerous flexible hoses and bellows in addition. 
The results of the GM FE analyses are transferred to the local models in terms of forces and moments, in terms of displacements in case sub-modelling procedures are used, or the local component model is embedded in the GM [5-9,26].

Besides for evaluation of structural integrity, the global and local model results were also used for the definition of positions for the mechanical instrumentation of the structure [33].

\section{Lessons learned during design phase}

\subsection{Strong and experienced team}

Unique devices like W7-X, ITER and other large fusion experiments require strong and experienced teams for structural analysis from the beginning of the project. The team should further grow gradually in size and experience towards construction of the device.

An example shall demonstrate what might happen if the manpower is not sufficient: The W7$\mathrm{X}$ planar coil case is a bolted and pinned structure. Due to lack of resources, modeling and analysis of the case was originally performed only as for solid body, and this was judged as good enough. As a result, the deformation of the coil was considerably underestimated. In addition, the detailed analysis showed complete breakage of the fasteners and overloading of the winding pack. The correction measures which had to be applied to already manufactured coils included drilling and installation of 300-400 additional pins in the coil cases (e.g. Fig. 4), and change of the planar support elements [8].

A considerable number of local models had to be created to analyze critical components of the machine. Most of the local analyses were carried out in collaboration with sub-contractors in the framework of national and international contracts [5-9]. The experience convinces that such external contracts are to be closely followed by advanced specialists of the home team. Complex analysis of components with non-linear behaviour is prone to errors and has to be carefully checked by reruns of the analysis by the team. 


\subsection{Benchmark of complex FE models}

Complex FE models similar to the W7-X global model of the magnet system are to be definitely benchmarked with independent alternative models of the same complexity. The GM is always a compromise between reasonable representation of main features of the subsystems, computational time, and simplicity for debugging. Therefore, studies of model reliability and sensitivity as well as benchmarking processes are extremely important. During benchmarking $[6,12]$ between three independent FE models more than 30 errors have been found and fixed in parameters, boundary conditions and post-processing routines. The benchmarking process was implemented in parallel with the production and construction process. Inaccuracies which were found required immediate modifications of the structure including reinforcement of welds, introduction of additional reinforcement ribs and pins, cut and re-weld of blocks for critical supports (see Fig. 5), and other corrections. The process was a challenging task due to existing interfaces with already manufactured coils and components, and space restrictions.

\subsection{Tests of materials and critical components}

FE analysis has to be complemented by tests of materials and full, partial or scaled prototypes for highly loaded structural elements.

The "state of art" fusion devices are always beyond developed and accepted criteria. In general, W7-X structural design criteria for the cryogenic magnet system follow the ones developed for ITER in 2004. However, criteria for critical components, welds, handmade insulation, and unique elements were extended and elaborated on the basis of extensive test programs and FE limit analyses taking into account also material serration effects $[31,32]$. Worth to mention are particularly test programs supported by intensive structural analysis for highly loaded NSEs [13,14], CSEs [15], cryolegs [16] and conductor connections [17], as well 
as for the mechanical quench test on the superconducting NPC type 2 under current $[27,28]$. Quality assurance on the material batches for incoming material is also very important [34]. The requirements for structural material properties are high, and variations are usually not acceptable. The test program for the magnet system has been successfully completed by tests of EKagrip ${ }^{\circledR}$ friction enhancing foils for elements to be installed at the module separation interface [26].

\subsection{Parametrization of FE models}

Final FE models have to be well structured and parameterized as far as reasonable in order to minimize evaluation delays in case of component non-conformities and modifications.

The first set of local models was created without parameterization (e.g. [18]) and subjected to considerable modifications due to design evolution. However, for the next iteration with final tuning of the parameters and analysis of assembly tolerances the approach was not efficient. Small modification of parameters required considerable efforts, and it was sometimes easier to rebuild the FE model from scratch rather than adapt the created model. Therefore, it was decided to create parametric models, well structured and easy to reuse (e.g. [19]). The new approach, in-spite of the initial requirement for higher resources, proved its efficiency during analyses of a considerable number of non-conformities, tolerance variations, and evolution of design loads [20]. Local models for detail analysis of critical components are mostly parametric now.

\subsection{Safety margin and prediction of tolerances}

Reasonable safety margins are to be assumed from the start for both the structural analysis results and manufacturing as well as assembly tolerances.

Non-linearities of the systems, model simplifications, model uncertainties and possible 
variations of nominal parameters as well as material properties require application of some safety margins on top of the obtained FE results. The following margins were established for the project and used for the configuration space control [21,22] as well as structural analysis: (1) scale factor 1.5 for displacements caused by bolt preload, dead weight and electro-magnetic load application. No scale factor was applied for cool-down, but the factor 1.1 for baking of the PV; (2) scale factor 1.2, 1.1 and 1.0 for the forces, moments and stresses extracted from the global models with nominal, likely and extreme parameter sets respectively. The experience during machine assembly shows that the scale factor for displacements covers all uncertainties while the factor for the forces and moments was not able to cover influences of original underestimations of NSE gap tolerances on forces and moments in critical supports. The latter resulted in requirements to reanalyze the GM, revise design load ranges for critical components, and to restart the evaluation of machine limits on the basis of local analysis under new design loads.

\section{Current and future activities}

Structural analysis of the magnet system concentrates now on the verification of elements to be installed in the module separation interface (see e.g. [26]), the support of assembly processes, reliable prediction of the stellarator structural behaviour at the maximum design value of 3T, establishing limits for machine operation, and study of new plasma scenarios and operational regimes. A further task is structural simulation of fault scenarios with deduction of corresponding operation instructions. FE fracture mechanics analyses taking into account plasticity are still on-going to confirm the acceptance of detected cracks which was originally made on the basis of a simplified semi-analytical approach.

The cryostat global analysis is being performed for specified normal and abnormal load regimes, and sometimes followed by modifications of components and interfaces not yet finally decided. Local analyses of critical components shall confirm the structural reliability of 
the system. Main attention is paid to non-standard port welds and vessel supports which are structurally verified by static and cyclic analyses (e.g. Fig. 6).

The efforts of the IPP FE analysis group now gradually migrate to wider support of the diagnostic and in-vessel component design $[23,29,30]$.

\section{Conclusions}

Resolving the main critical issues in the design of a complex fusion device is only possible with an accurate prediction of the system behaviour. A strategy for extensive FE structural analyses has to be developed and implemented in order to validate the adopted design solutions, and to perform a proper choice of parameters. The FE model tree should also provide the possibility to analyze nonconformities reported by manufacturers, and to accept or reject inconsistencies with the reference design. In order to accelerate assessment processes, parametric FE models are to be created as far as possible. Incoming test results concerning structural materials and full or partial prototypes of highly loaded components are important parts of structural analysis and to be carefully followed.

Successful execution of such demanding tasks is only possible with a strong and experienced team whose core is involved in the project from the beginning.

The lessons learned during the exciting and laborious course of structural analysis of W7-X are certainly valuable for design and construction of any large fusion device and might help to minimize risks of errors, delays in construction, and requirements for component modifications. In addition, the obtained experience is a basis for stellarator reactor studies in IPP $[24,25]$. 


\section{References}

[1] V. Erckmann, V. Hartfuss, H.-J. Kick, M. Renner, H. Sapper, F. Schauer, et al., The W7X project: scientific basis and technical realisation, in: 17th IEEE/NPSS Symposium on Fusion Engineering I, 1997, p. 48.

[2] H.-S. Bosch, V. Erckmann, R. König, F. Schauer, R. Stadler, A. Werner, Construction of Wendelstein 7-X - engineering a steady state stellarator, in: $23^{\text {rd }}$ Symposium on Fusion Engineering, 2009, ISBN: 978-1-4244r-r2636-2.

[3] D. Hartmann, Building a large cryogenic device - experience from W7-X, in: 26th Symposium on Fusion Technology, IT5, 2010.

[4] T. Koppe, A. Cardella, J. Reich, B. Missal, B. Hein, R. Krause, et al., Manufacturing and assembly status of main components of the Wendelstein 7-X cryostat, Fusion Eng. Des. 84 (2009) 1099-1103.

[5] A. Tereshchenko, V. Bykov, F. Schauer, M. Ye, S. Weißflog, T. Andreeva, Structural analysis of the W7-X cryogenic pipe system, Fusion Eng. Des. 84 (2009) 1833-1837.

[6] V. Bykov, F. Schauer, K. Egorov, A. Tereshchenko, P. van Eeten, A. Dübner, et al., Structural analysis of W7-X: overview, Fusion Eng. Des. 84 (2009) 215-219.

[7] V. Bykov, F. Schauer, K. Egorov, P. Van Eeten, C. Damiani, A. Dübner, et al., Structural analysis of W7-X: main results and critical issues, Fusion Eng. Des. 82 (2007) 15381548.

[8] V. Bykov, F. Schauer, P. Van Eeten, K. Egorov, A. Tereshchenko, A. Duebner, et al., Main results and critical issues of W7-X structural analysis, in: 22 IEEE/NPS Symposium on Fusion Engineering, 2007, ISBN: 978-1-4244-1194-8. 
[9] V. Bykov, M. Gasparotto, N. Jaksic, K. Egorov, M. Sochor, L. Sonnerup, et al., Strategy of structural analysis of W7-X magnet system, in: 21 IEEE/NPS Symposium on Fusion Engineering, paper 04 11, 2006, ISBN: 0-4244-0150-X.

[10] A. Dübner, D. Zacharias, M. Nagel, V. Bykov, F. Schauer, M. Ihrke, Structural analysis of the W7-X cryogenic pipe system, Fusion Eng. Des. 84 (2009) 694-697.

[11] O. Neubauer, A. Charl, G. Czymek, B. Giesen, M. Sauer, L. Scheibl, et al., The busbar system for Wendelstein 7-X prepared for assembly and operational loads, Fusion Eng. Des. 84 (2009) 1416-1419.

[12] N. Jaksic, P. van Eeten, M. Sochor, V. Bykov, F. Schauer, Analysis of the magnet support structure for the plasma fusion experiment Wendelstein 7-X, Computers and Structures (2011).

[13] P. van Eeten, D. Hathiramani, V. Bykov, A. Cardella, A. Dudek, J. Holluba, et al., Design and test of the support element of the W7-X superconducting magnets, in: 22nd Symposium on Fusion Engineering, 2007, ISBN: 978-1-4244-1194-8.

[14] D. Hathiramani, J. Lingertat, P. van Eeten, M. Sochor, M. Laux, V. Bykov, et al., Fullscale friction test on tilted sliding bearings for Wendelstein 7-X coils, Fusion Eng. Des. 84 (2009) 899-902.

[15] A. Dudek, V. Bykov, P. Czarkowski, D. Hathiramani, M. Nitz, F. Schauer, et al., Verification tests of critical bolted connections of the W7-X coils, Fusion Eng. Des. 84 (2009) 703-706.

[16] K. Egorov, V. Bykov, F. Schauer, P. van Eeten, Structural analysis of Wendelstein 7-X magnet weight supports, Fusion Eng. Des. 84 (2009) 722-728. 
[17] J. Fellinger, A. Dudek, D. Zacharias, H. Dutz, K. Risse, D. Hathiramani, et al., Weld integrity of the superconducting cable aluminium jackets of W7-X, Fusion Eng. Des. 84 (2009) 766-771.

[18] G. Krzesinski, T. Zagrajek, P. Marek, R. Dobosz, P. Czarkowski, K.J. Kurzydłowski, et al., FEM analysis of coil support connections in the Wendelstein 7-X magnet system, Fusion Eng. Des. 82 (2007) 1574.

[19] Ł. Ciupinski, G. Krzesinski, K. Kurzydlowski, P. Marek, T. Zagrajek, V. Bykov, et al., Evaluation of the structural mechanical behavior of W7-X central support connections by means of semi-automated FE analysis, Fusion Eng. Des. 84 (2009) 613-617.

[20] P. Czarkowski, V. Bykov, A. Dudek, Structural analysis of the central support elements for the Wendelstein 7-X magnet system, Fusion Eng. Des. 84 (2009) 636.

[21] C. Baylard, D. Hartmann, H. Greve, F. Herold, Configuration space control for Wendelstein 7-X, Fusion Eng. Des. 84 (2009) 435.

[22] R. Brakel, C. Baylard, H. Greve, D.A. Hartmann, F. Herold, D. Pilopp, et al., Component design in tight areas in the cryostat of Wendelstein $7-\mathrm{X}$ - configuration management and control, in: 23rd Symposium on Fusion Engineering, 2009, ISBN: 978-1-4244r-r2635-5.

[23] M.Y. Ye, M. Hirsch, R. König, M. Laux, H. Thomsen, A. Weller, et al., Thermomechanical analysis of plasma facing components of diagnostics in the Wendelstein 7-X stellarator, Fusion Eng. Des. 84 (2009) 2002-2007.

[24] F. Schauer, H. Wobig, K. Egorov, V. Bykov, M. Köppen, Extrapolation of the W7-X magnet system to reactor size, Contrib. Plasma Phys. 50 (2010) 750.

[25] F. Schauer, K. Egorov, V. Bykov, Coil winding pack FE-analysis for a HELIAS reactor, in: 26th Symposium on Fusion Technology, P2-53, 2010. 
[26] A. Dudek, A. Benndorf, V. Bykov, P. van Eeten, J. Fellinger, D. Hathiramani, et al., Bolted coil support at the W7-X module interface, in: 26th Symposium on Fusion Technology, P3-71, 2010.

[27] D. Hathiramani, T. Bergmann, V. Bykov, P. Chen, W. Dänner, A. Dudek, et al., Stability test of a superconducting W7-X coil with respect to mechanical disturbances, IEEE Trans. Appl. Supercond. 20 (2010) 543-546.

[28] J. Fellinger, S. Freundt, D. Hathiramani, V. Bykov and F. Schauer, Dynamic response analysis of superconducting coils in Wendelstein 7-X, and mechanical quench test, in: 26th Symposium on Fusion Technology, P4-78, 2010.

[29] M. Köppen, M. Hirsch, J. Ernst, V. Bykov, F. Schauer, W. Vliegenhart, Thermomechanical analysis of retro-reflectors for interferometry and polarimetry in W7X, in: 26th Symposium on Fusion Technology, P3-70, 2010.

[30] M. Ye, V. Bykov, F. Schauer, A. Peacock, Thermo-mechanical analysis of the W7-X divertor, in: 26th Symposium on Fusion Technology, P2-65, 2010.

[31] Ł. Ciupinski, G. Krzesinski, P. Marek, T. Zagrajek, K. Kurzydlowski, J. Fellinger, et al., Limit analysis of W7-X critical magnet system components with consideration of material serration effect, in: 26th Symposium on Fusion Technology, P3-62, 2010.

[32] E. Briani, C. Gianini, F. Lucca, A. Marin, V. Bykov, J. Fellinger, Limit analysis of narrow support elements in W7-X considering the serration effect of the stress-strain relation at 4K, in: 26th Symposium on Fusion Technology, P4-115, 2010.

[33] P. Kallmayer, Ch. Caldwell-Nichols, P. Chen, M. Nitz, F. Scherwenke, Instrumentation of W7-X cryo structure with advanced strain gauge sensors, in: $26^{\text {th }}$ Symposium on Fusion Technology, P4-77, 2010. 
[34] W. Dänner, D. Hathiramani, F. Schauer, S. Freundt, Cryogenic materials data base for the W7-X magnet system, Cryogenics 50 (2010) 728-736. 
Figures

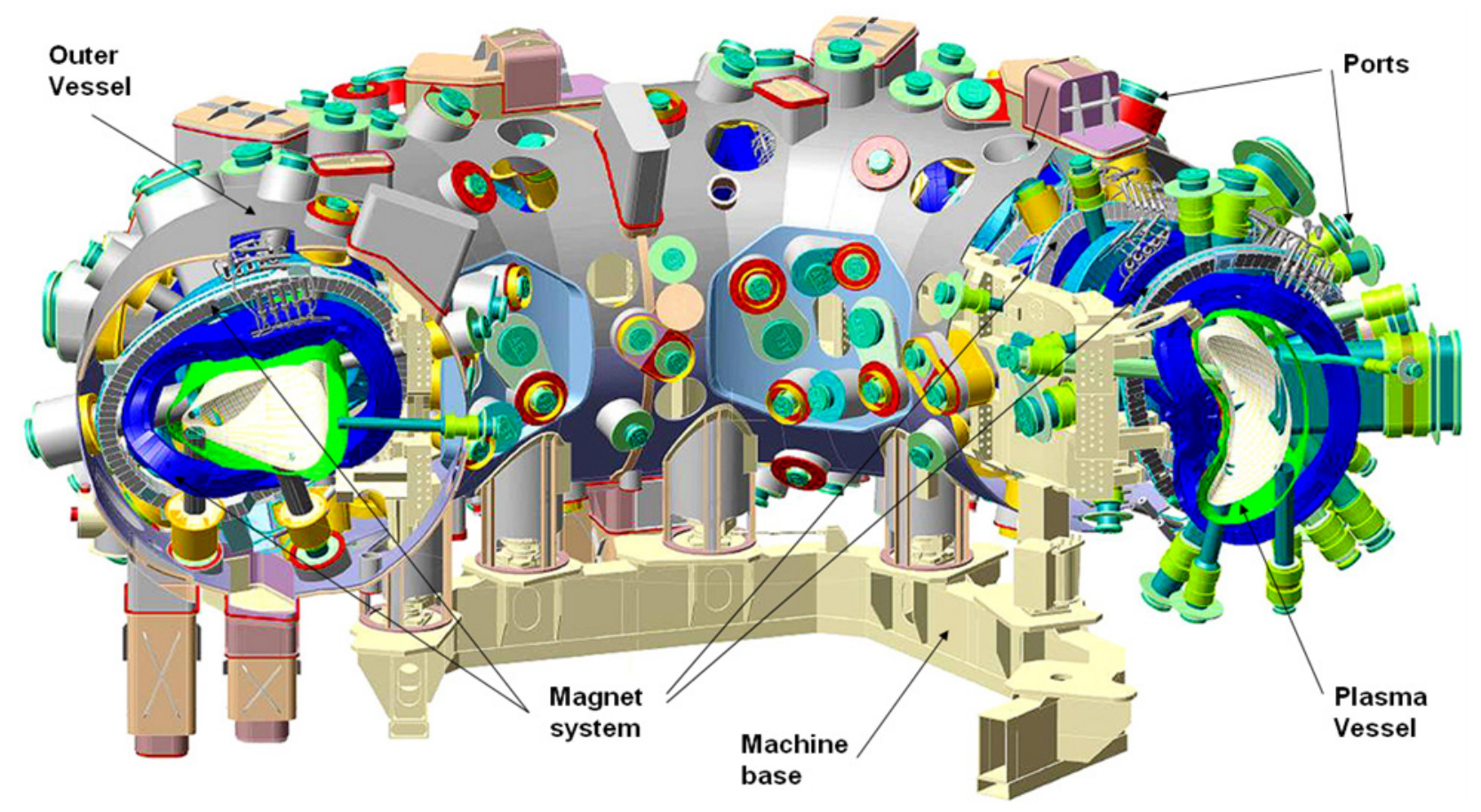

Fig. 1. CAD view of W7-X. 


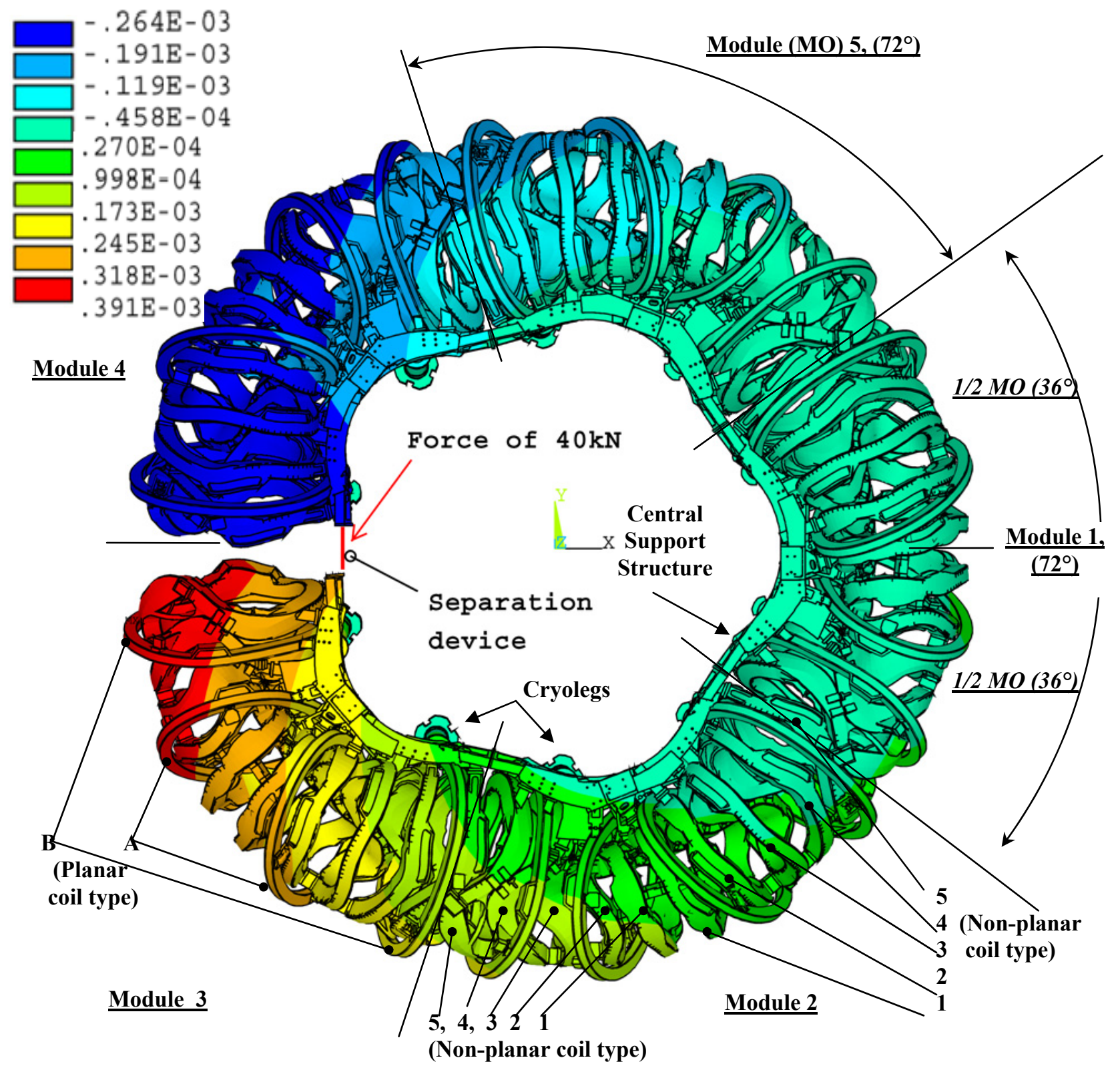

Fig. 2. ANSYS $360^{\circ}$, global model for magnets system. Toroidal movement $(\mathrm{m})$ during assembly, deformation shown highly exaggerated: case of central support structure flange spreading between Module 3 and Module 4 by $40 \mathrm{kN}$ force. 


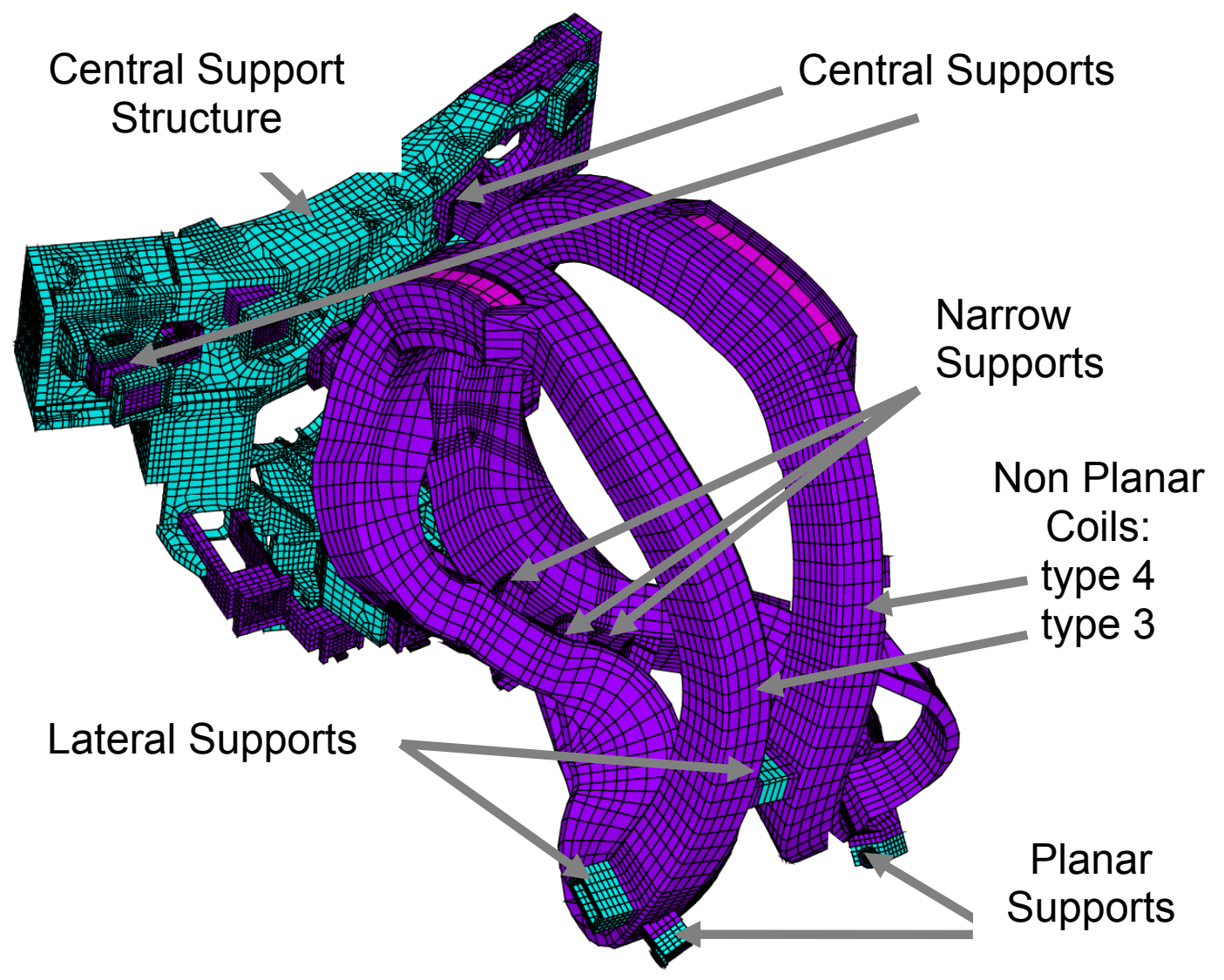

Fig. 3. 3-D view of the typical magnet support elements. Fragment of ANSYS Global Model. 


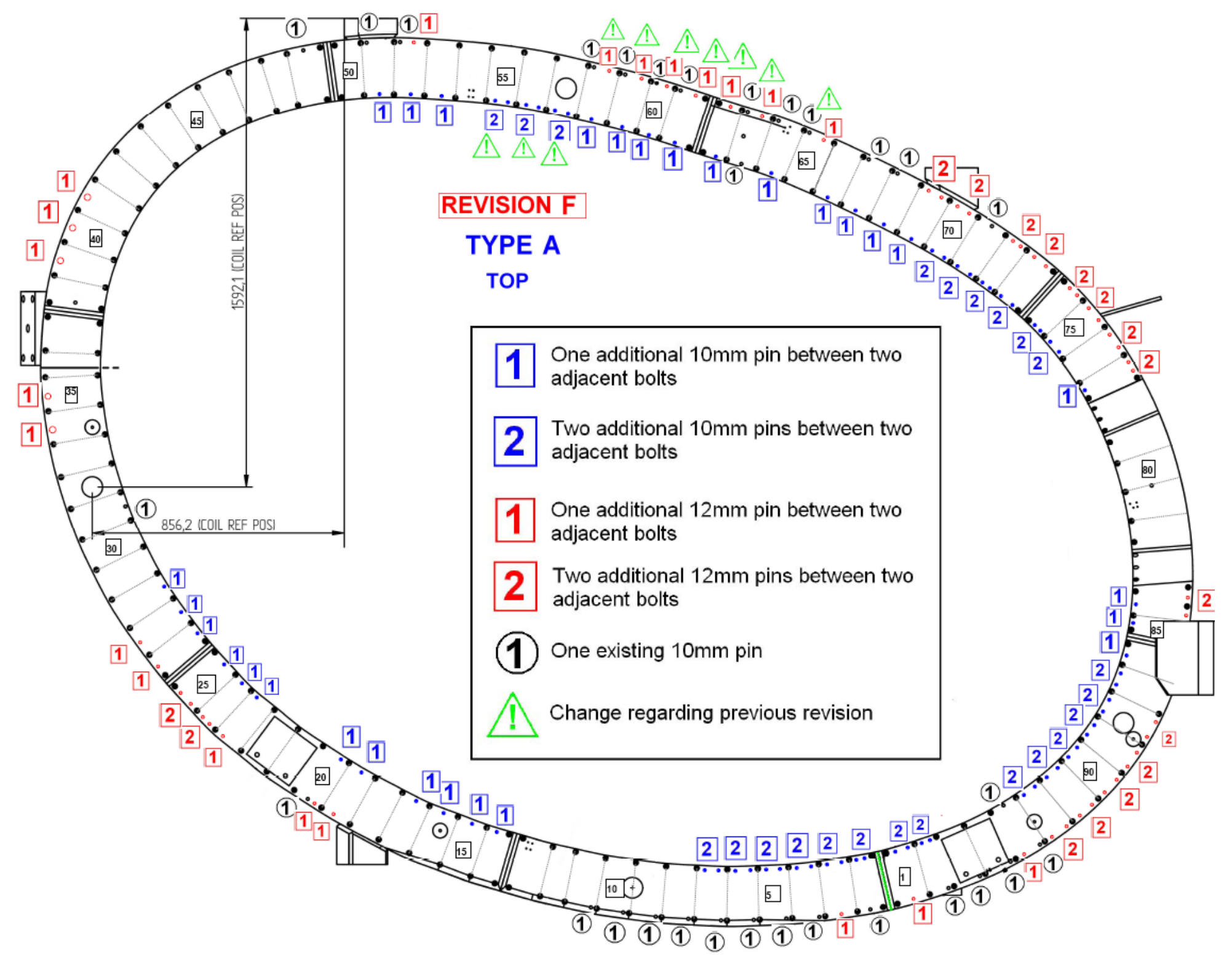

Fig. 4. Planar coil type A: top lid reinforcement by additional pins. 


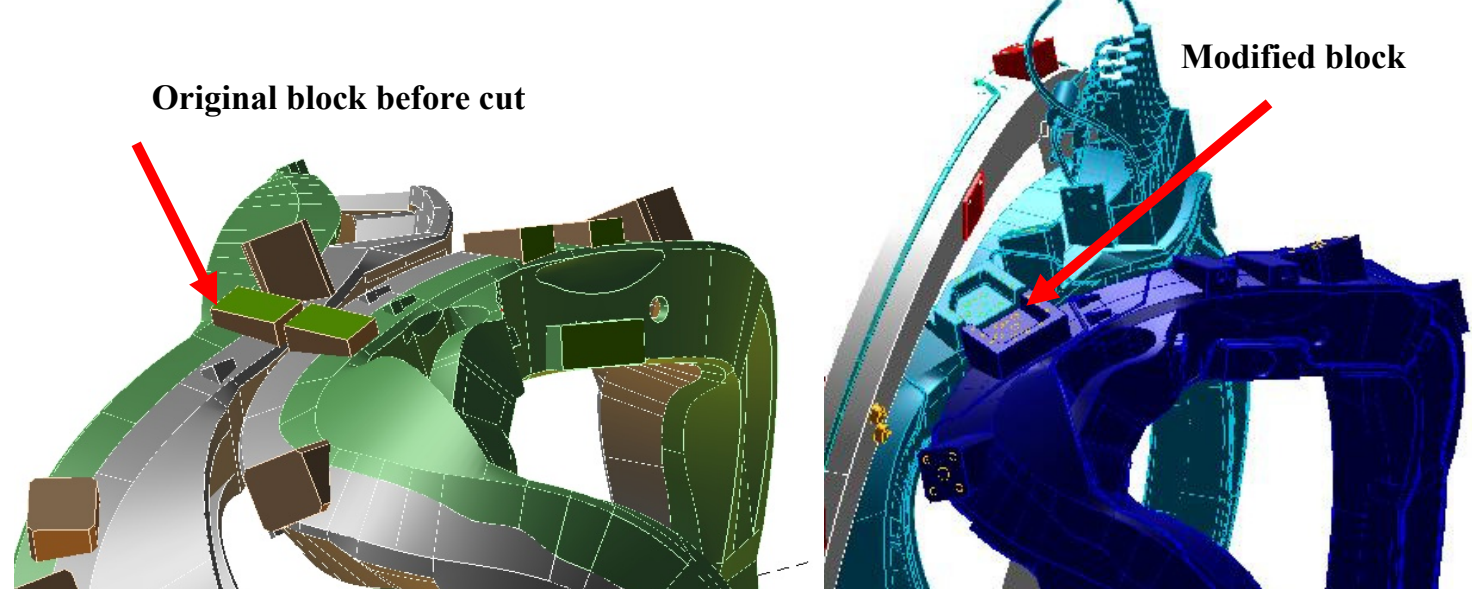

Fig. 5. Lateral support 5-5: block on non-planar coils type 5 before and after modification. 


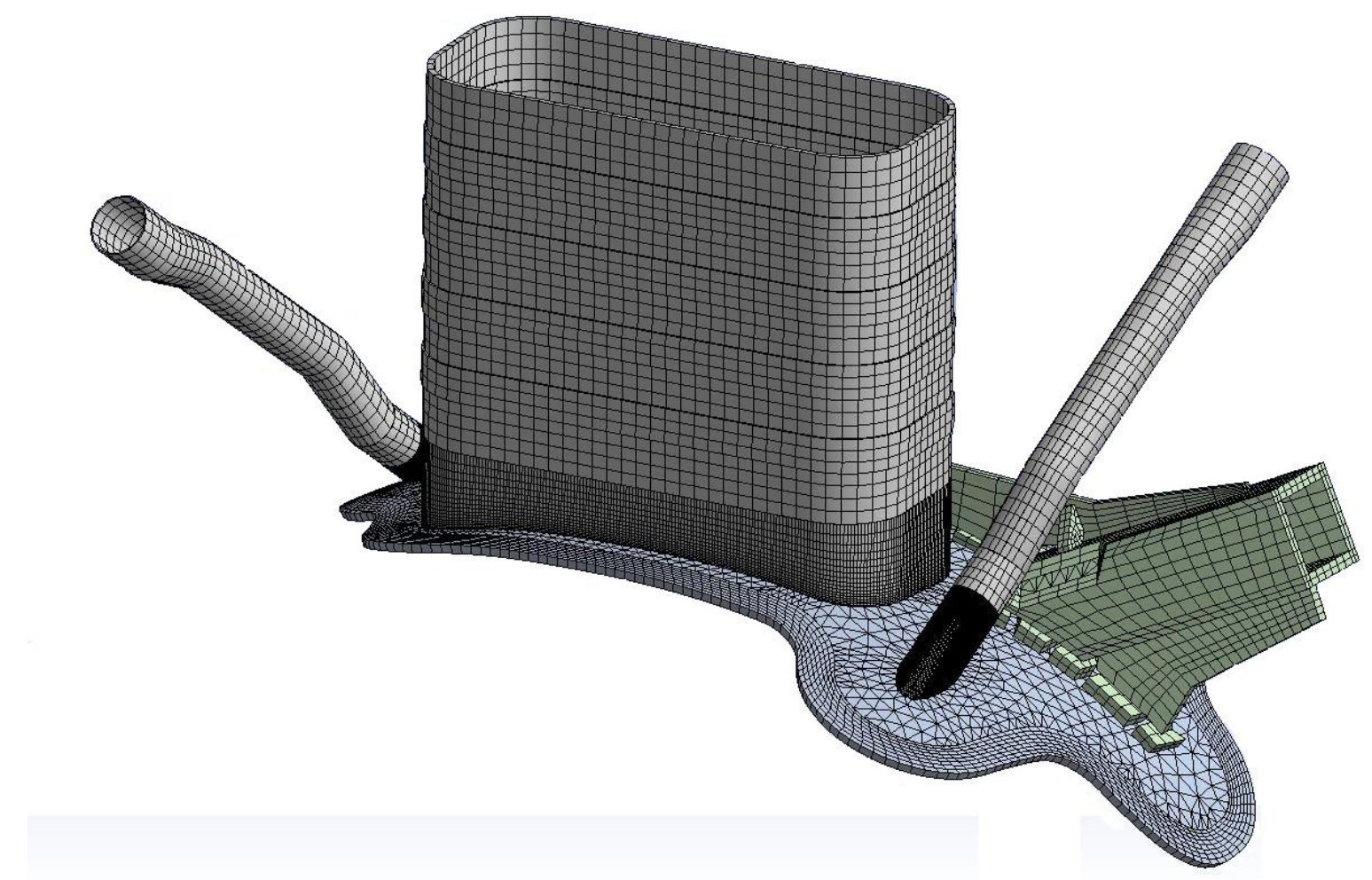

Fig. 6. Detail FE local model for limit analysis of critical port welds under boundary conditions extracted from cryostat GM. 